\title{
Fabrication and Characterization of a W-Band Cylindrical Dielectric Resonator Antenna-Coupled Niobium Microbolometer
}

\author{
M. Abdel-Rahman, ${ }^{1}$ M. Kamran Saleem, ${ }^{2}$ Najeeb Al-Khalli, ${ }^{2}$ Nacer Debbar, ${ }^{2}$ \\ Majeed A. S. Alkanhal, ${ }^{2}$ and Abdelrazik Sebak, \\ ${ }^{1}$ Prince Sultan Advanced Technologies Research Institute (PSATRI), King Saud University, Riyadh 11421, Saudi Arabia \\ ${ }^{2}$ Electrical Engineering Department, King Saud University, Riyadh 11421, Saudi Arabia \\ ${ }^{3}$ Electrical and Computer Engineering Department, Concordia University, Montreal, QC, Canada H3G 1M8 \\ ${ }^{4}$ KACST Technology Innovation Center in RFTONICS, King Saud University, Riyadh 11421, Saudi Arabia
}

Correspondence should be addressed to M. Abdel-Rahman; mabdelrahman@ksu.edu.sa

Received 1 October 2014; Revised 28 December 2014; Accepted 28 December 2014

Academic Editor: Paolo Burghignoli

Copyright $\odot 2015$ M. Abdel-Rahman et al. This is an open access article distributed under the Creative Commons Attribution License, which permits unrestricted use, distribution, and reproduction in any medium, provided the original work is properly cited.

\begin{abstract}
We report on the fabrication and characterization of a novel antenna-coupled detector configuration for detection at $94 \mathrm{GHz}$, a coplanar waveguide- (CPW-) fed, slot-excited twin dielectric resonator antenna- (DRA-) coupled niobium (Nb) microbolometer. The antenna is based on two low permittivity cylindrical dielectric resonators (CDRs) excited by rectangular slots placed below the CDRs. The antenna resonant currents are fed to an $\mathrm{Nb}$ microbolometer by the means of a CPW feed. The ceramic DRA structure is manufactured using a novel fabrication process that enables patterning an SU-8-Alumina $\left(\mathrm{Al}_{2} \mathrm{O}_{3}\right)$ nanopowder composite using conventional photolithography. The detector measured a voltage responsivity of $0.181 \mathrm{~V} / \mathrm{W}$ at a modulation frequency of $150 \mathrm{~Hz}$. The detector measured a time constant of $1.94 \mu \mathrm{s}$. The antenna radiation pattern of the developed detector configuration was measured and shows a good agreement with the simulation.
\end{abstract}

\section{Introduction}

Antenna-coupled microbolometers have been investigated for imaging applications in the millimeter wave (MMW) and terahertz (THz) spectral regions [1-4]. Electromagnetic waves irradiating an antenna-coupled microbolometer detector are sensed by the resonant antenna. The induced resonant currents are dissipated in the microbolometer located at the antenna feed causing its resistance to change. The resistance change can then be transformed into an output voltage that is proportional to the incident power of the electromagnetic radiation impinging the antenna-coupled microbolometer.

Dielectric resonator antennas (DRAs) have been widely investigated in microwave and MMW frequency bands due to several attractive properties [5-11]. DRAs operating in the microwave and MMW frequency bands have shown high radiation efficiencies when compared to printed metallic antennas. This is mainly due to the absence of conductor and surface wave losses, which are greatly dominant in printed metallic antennas. In addition, DRAs can be designed in various shapes and can be configured to have different excitation modes and feeding schemes which offer great design flexibilities. It is of high interest to explore the benefits arising from coupling high gain DRAs with microbolometers. However, coupling microbolometers requires differential feeds for signal bias and readout to regular common DRAs and similar high gain single ended antennas and was not previously explored. Recently, a design was presented by Saleem et al. for a novel antenna-coupled sensor configuration that explores the coupling of DRAs to differential feed sensors [12]. The design explored a coplanar waveguide- (CPW-) fed, slot-coupled cylindrical DRA- (CDRA-) coupled sensor for $94 \mathrm{GHz}$ detection applications. The antenna was based on two cylindrical dielectric resonators (CDRs) excited by means of 


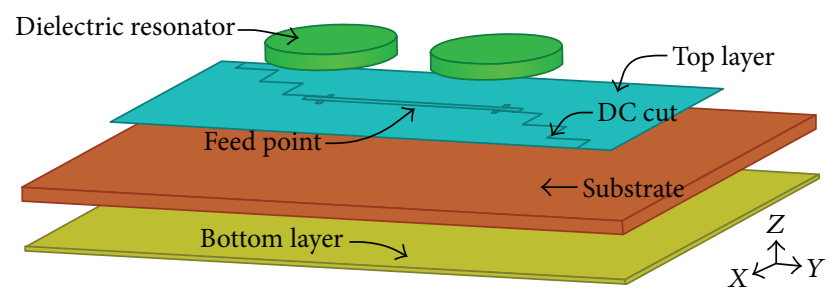

Figure 1: Three-dimensional schematic of the designed antennacoupled microbolometer configuration.

rectangular slots placed below the CDRs where the HEM $\mathrm{H}_{11 \Delta}$ mode resonating at $94 \mathrm{GHz}$ is generated within the CDRs. Coplanar waveguides were used to feed the antenna resonant currents to the sensor which is placed at the center of the CPW. Direct current (dc) cuts were introduced in the top ground plane to allow for sensor bias and detection of signal readout. In this paper we utilize the antenna-coupled sensor design presented by Saleem et al. [12] and we report on the fabrication and characterization of a coplanar waveguide(CPW-) fed, slot-coupled cylindrical DRA- (CDRA-) coupled $\mathrm{Nb}$ microbolometer for detection applications at $94 \mathrm{GHz}$.

\section{Detector Design}

The CDRA-coupled $\mathrm{Nb}$ microbolometer detector was designed for an operating frequency of $94 \mathrm{GHz}$ [12]. The 3D model of the detector structure is shown in Figure 1. The designed antenna is a dielectric resonator antenna placed on a quartz substrate. The quartz substrate $\left(\varepsilon_{r}=3.78\right)$ with a thickness $\mathrm{th}_{\text {sub }}=300 \mu \mathrm{m}$ is sandwiched between two thin aluminum (Al) layers of thickness thalu $=0.22 \mu \mathrm{m}$ each. The top aluminum layer is divided into two equal and electrically isolated parts by means of CPW, staircase dc cuts, and lumped port as a feed point. The division of top aluminum layer allows for $\mathrm{dc}$ biasing of the microbolometer. The two CDRs on the top are excited by means of rectangular slots coupled with CPW lines on the top aluminum layer. The bottom side of substrate is fully coated with $\mathrm{Al}$ and acts as antenna ground plane. The radius and height of $\operatorname{CDR}\left(\varepsilon_{r}=4\right)$ are $1.41 \mathrm{~mm}$ and $350 \mu \mathrm{m}$, respectively, resulting in $\mathrm{HEM}_{11 \Delta}$ mode at $94 \mathrm{GHz}$ whereas the center to center distance between the two CDRs is $3.86 \mathrm{~mm}\left(1.2 \lambda_{o}\right)$. The relative permittivity of the CDR material, $\varepsilon_{r}=4$, was theoretically estimated using Lichtenecker-Rother mixing law equation [13] and experimentally realized using a mixture of SU-8 photoresist with Alumina-alpha $\left(\mathrm{Al}_{2} \mathrm{O}_{3}\right)$ nanopowder.

In Figure 2 the top view of detector is shown with various design parameters. The red dotted area is zoomed for a more detailed view of excitation slot, CPW feeding lines, and microbolometer placement. The microbolometer was designed with dimension of $10 \mu \mathrm{m} \times 3 \mu \mathrm{m}$. The optimized dimensions of the structure are $P_{w}=0.01 \mathrm{~mm}, W=$ $0.19 \mathrm{~mm}, G=0.02 \mathrm{~mm}, W_{s}=0.103 \mathrm{~mm}, L_{\text {stub }}=0.417 \mathrm{~mm}$, $C_{\text {off }}=0.16 \mathrm{~mm}, L_{s}=0.75 \mathrm{~mm}, C_{\text {th }}=0.013 \mathrm{~mm}, C_{L}=1 \mathrm{~mm}$, $S_{\text {off }}=0.06 \mathrm{~mm}, L_{1}=14 \mathrm{~mm}, L_{2}=11.68 \mathrm{~mm}, W_{1}=10 \mathrm{~mm}$, and $W_{2}=5.82$.

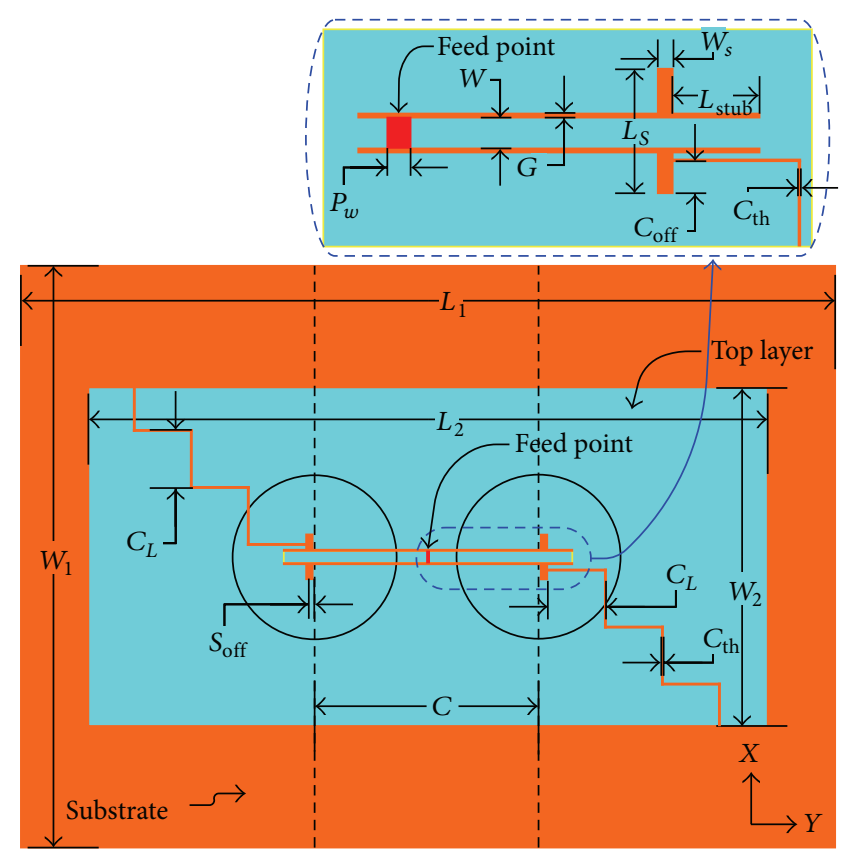

FIGURE 2: Top view of the designed antenna-coupled microbolometer configuration.

\section{Detector Fabrication}

The detector fabrication process involved three main layers. The first layer was for the formation of the antenna ground plane, the coupling slots, the CPW, and the staircase dc bias cuts. The second layer involved the fabrication of the microbolometer, and the third layer was used for patterning the DRA.

The antenna-coupled detector was fabricated on a $300 \mu \mathrm{m}$ thick quartz substrate. The antenna ground plane was formed by depositing a $220 \mathrm{~nm}$ layer of aluminum (Al) on the quartz substrate. Aluminum was deposited using dc magnetron sputtering at $150 \mathrm{~W}$ of power at a chamber base pressure of $1 \times 10^{-6}$ Torr and an argon (Ar) pressure of 3 mTorr. Rohm \& Haas S1813 positive photoresist was spun over the Al thin film. The photoresist was exposed through the antenna photomask for $3 \mathrm{~s}$ at $175 \mathrm{~W}$ of ultraviolet (UV) power at a wavelength of $365 \mathrm{~nm}$ using an NXQ 4004 contact mask aligner. The photoresist was then developed for $90 \mathrm{~s}$ in Rohm \& Haas MIF 319 developer. The exposed areas of the $\mathrm{Al}$ were etched using sputter etching at an RF power of $30 \mathrm{~W}$, a substrate holder rotation of $40 \mathrm{rpm}$, a chamber base pressure of $1 \times$ $10^{-6}$ Torr, and an Ar pressure of 3 mTorr. Sputter etching was performed for 64 minutes on seven steps with a cool down interval of 7 minutes in order to prevent the resist from thermal cross-linking, while the other parts (ground plane) remain protected by the photoresist. Then the photoresist was stripped off using Rohm \& Haas 1165 remover with the aid of ultrasonic power at $80^{\circ} \mathrm{C}$ for 15 minutes. The patterned first layer on quartz substrate is shown in Figure 3. The patterned layer consists of the exiting slots, the CPW, and the staircase dc bias cut lines. 


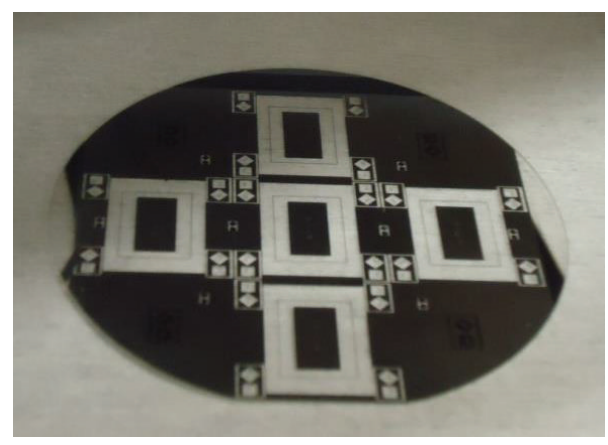

FIgUre 3: Patterned Al ground plane with CPWs and DC bias cuts for five detectors on a 3 -inch quartz wafer.

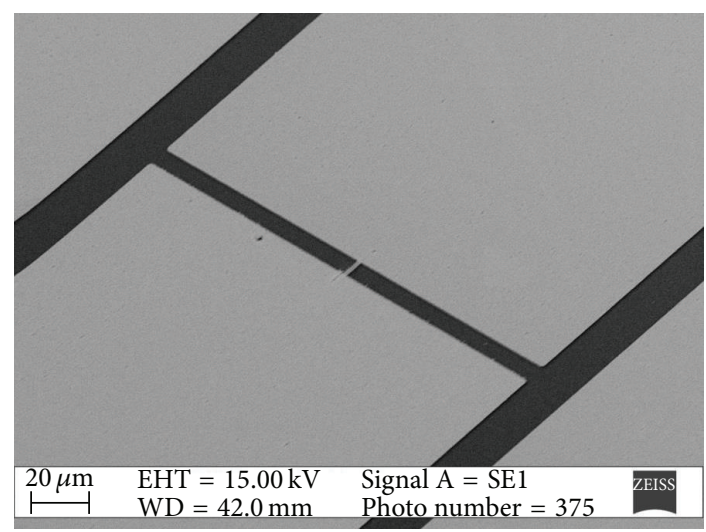

FIGURE 4: An SEM micrograph showing the Nb microbolometer located at the center of the CPW structure.

The $\mathrm{Nb}$ microbolometer was fabricated using photolithography and conventional liftoff processes. First, Rohm \& Haas S1813 positive photoresist was spun over the Al ground plane. The photoresist was then exposed through the microbolometer photomask and developed resulting in the removal of the photoresist from the microbolometer areas. A $137 \mathrm{~nm}$ thin film of $\mathrm{Nb}$ was then deposited covering the entire surface of the substrate using $\mathrm{dc}$ magnetron sputtering at $150 \mathrm{~W}$ of DC power at a chamber base pressure of $1 \times$ $10^{-6}$ Torr and an Ar pressure of 3 mTorr. The substrate is then immersed into a remover that dissolves the photoresist. The photoresist dissolves and the thin material above it was lifted off leaving only the deposited material in the areas intended for the microbolometer in the middle of the ground plane between the two CPW conductors that have been already patterned. Figure 4 shows a scanning electron microscope (SEM) micrograph for the patterned $10 \mu \mathrm{m} \times$ $3 \mu \mathrm{m} \mathrm{Nb}$ microbolometer placed between the CPW feed lines.

In the third layer (the CDRA patterning layer), approximately $2 \mathrm{~mL}$ of a mixture of SU-8 2150 photoresist with Alumina-alpha $\left(\mathrm{Al}_{2} \mathrm{O}_{3}\right)$ nanopowder was injected from syringe over a substrate having a single device ground plane. The $\mathrm{Al}_{2} \mathrm{O}_{3}$ nanopowder, from $\mathrm{MK}$ nano, constituted $22 \%$ of the total mixture weight, which will yield an $\varepsilon_{r}=4$ for the $\mathrm{SU}-8-\mathrm{Al}_{2} \mathrm{O}_{3}$ composite mixture. Before spin coating,

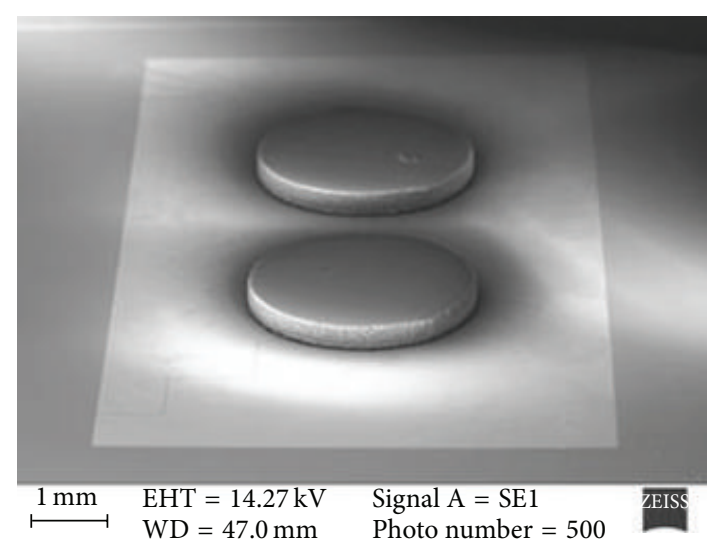

Figure 5: An SEM micrograph for twin DRAs on top of Al ground plane.

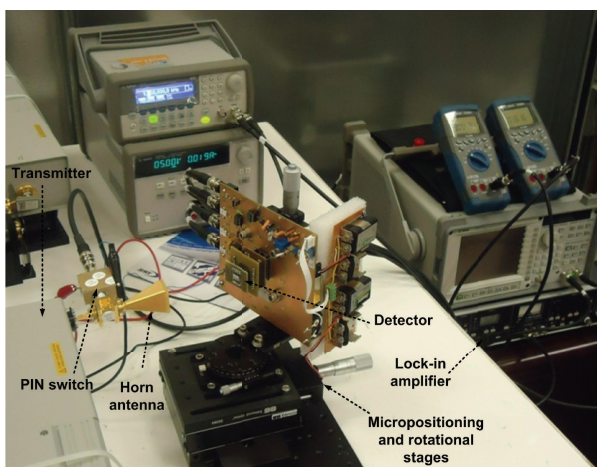

FIGURE 6: Experimental setup for antenna-coupled microbolometer characterization: the detector is being obliquely irradiated by a horn antenna beam that is modulated by a PIN switch.

the specimens were left for 3 minutes to allow the SU-8$\mathrm{Al}_{2} \mathrm{O}_{3}$ composite mixture to spread over the whole substrate. Spinning was done in two steps. First the wafer was accelerated at $100 \mathrm{rpm} / \mathrm{s}$ to a speed of $500 \mathrm{rpm}$ for $8 \mathrm{~s}$ to allow for a uniform distribution of the SU-8- $\mathrm{Al}_{2} \mathrm{O}_{3}$ composite mixture over whole substrate. In the second step, the wafer was accelerated at $400 \mathrm{rpm} / \mathrm{s}$ to a speed of $1450 \mathrm{rpm}$ for $35 \mathrm{~s}$ in order to get a film with thickness of $350 \mu \mathrm{m}$. To avoid thermal shock for the $\mathrm{SU}-8-\mathrm{Al}_{2} \mathrm{O}_{3}$ composite film during baking, the film temperature was gradually increased during soft baking using two different hot plates. Accordingly, the film was processed on the first hot plate at $50^{\circ} \mathrm{C}$ for 10 minutes and then on a second hot plate at $95^{\circ} \mathrm{C}$ for 108 minutes. The specimens were removed from the hot plate and allowed to cool down to room temperature. The SU-8- $\mathrm{Al}_{2} \mathrm{O}_{3}$ composite film was exposed through the CDR photomask for 5 minutes at $175 \mathrm{~W}$ of UV power at a wavelength of $365 \mathrm{~nm}$ using an NXQ 4004 contact mask aligner. The exposed areas resembling the CDRAs become cross-linked (insoluble in developer). The SU-8- $\mathrm{Al}_{2} \mathrm{O}_{3}$ composite film was then postbaked using two hot plates one at $50^{\circ} \mathrm{C}$ for 5 minutes and the second one at $95^{\circ} \mathrm{C}$ for 28 minutes. The SU-8 $-\mathrm{Al}_{2} \mathrm{O}_{3}$ composite film was then developed for 20 minutes using SU-8 developer 


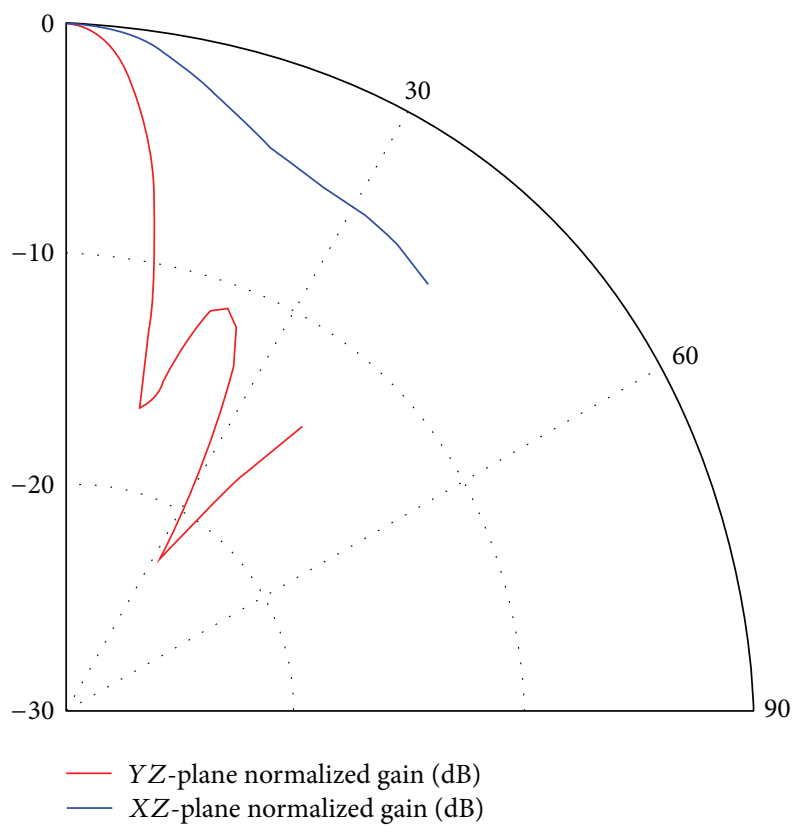

(a)

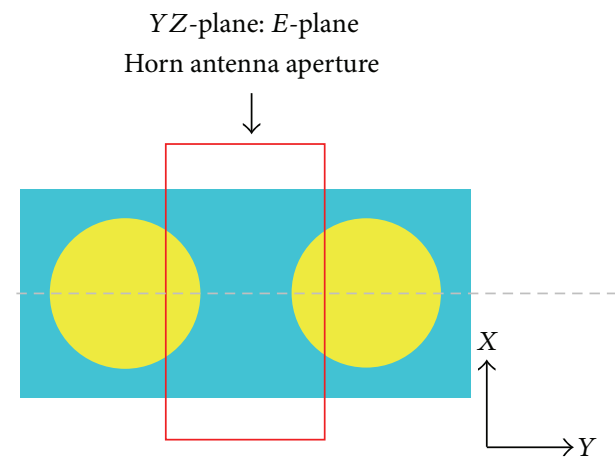

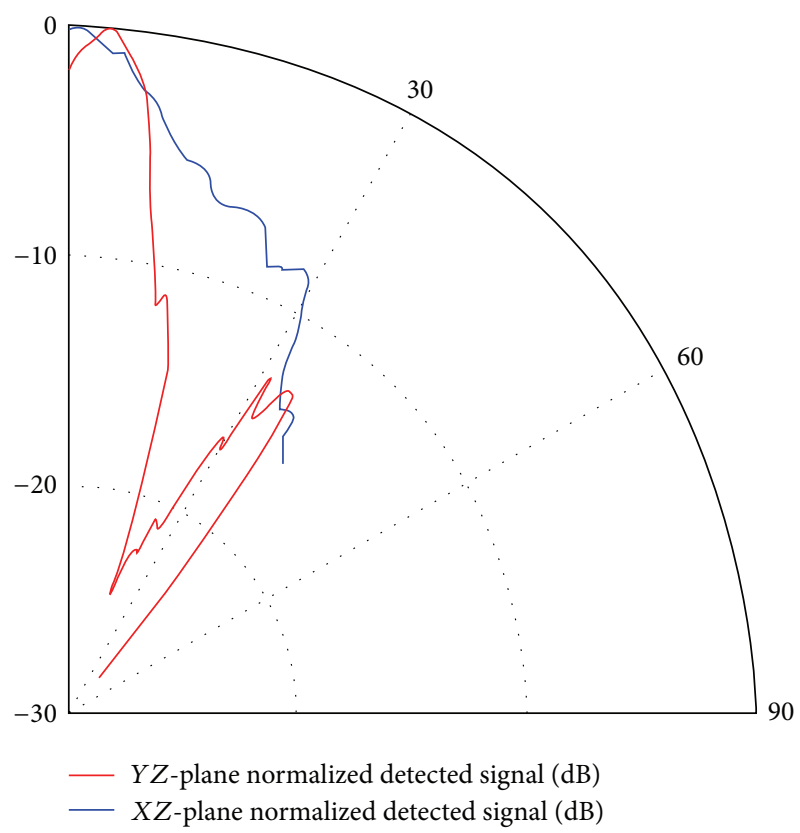

(b)

$X Z$-plane: $H$-plane

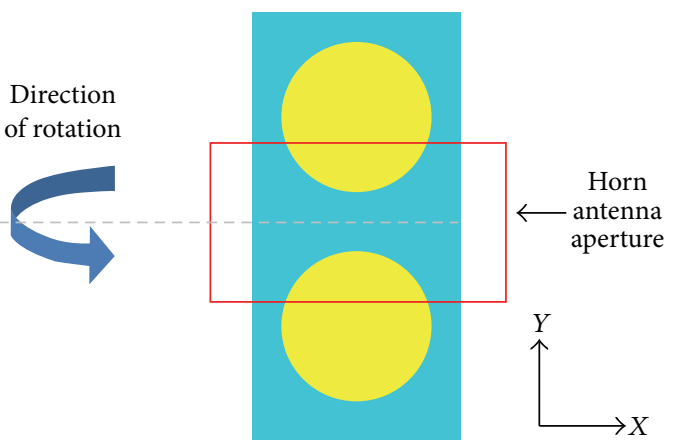

(c)

FIGURE 7: Comparison between (a) normalized simulated antenna gain, (b) normalized detected signal in $Y Z$ - and $X Z$-planes for a CDRAcoupled $\mathrm{Nb}$ microbolometer, and (c) a descriptive schematic for $E$ - and $H$-plane definition.

with hand stirring, and then isopropyl alcohol was used for rinsing the residual SU-8 photoresist. Finally, a second ground plane was deposited at the bottom surface of the quartz substrate where $220 \mathrm{~nm}$ of $\mathrm{Al}$ was coated using dc magnetron sputtering at $150 \mathrm{~W}$ of power at a chamber base pressure of $1 \times 10^{-6}$ Torr and an Ar pressure of 3 mTorr. Figure 5 shows an SEM micrograph of the fabricated detector.

\section{Characterization and Results}

A network analyzer transmitter module was utilized as the source of millimeter wave radiation. The $94 \mathrm{GHz}$ radiation emitted from Agilent E8361C network analyzer attached with N5260 $67-110 \mathrm{GHz}$ frequency extender module was modulated by a PIN switch at a modulation frequency of $150 \mathrm{~Hz}$. The power emitted by the frequency extender module is approximately $-2.5 \mathrm{dBm}$, estimated from the maximum power output level provided by the network analyzer manufacturer. The PIN switch has an insertion loss of $2.5 \mathrm{~dB}$. A $25 \mathrm{~dB}$ gain $\mathrm{W}$-band horn antenna was then used to irradiate the detector. The distance between the horn antenna and the detector was $3.2 \mathrm{~cm}$. All the measurements were taken at the point where the polarization of the incident wave produced the highest voltage response. The detector was mounted on a printed circuit board (PCB) with $\mathrm{Cu}$ pads, and the device was bonded to these $\mathrm{Cu}$ pads using an ultrasonic wire bonder. The detector was precisely positioned at the center of the irradiating beam using a 3-axis $(X, Y$, and $Z)$ micropositioning stage. The 3 -axis micropositioning stage was mounted on a manual rotational stage that was used to apply angular variations of 2 degrees for the purpose of performing radiation pattern measurements. For both $E$ - and $H$-plane measurements, the symmetrical axes of the antenna were aligned with the rotation axis of the rotational stage. 


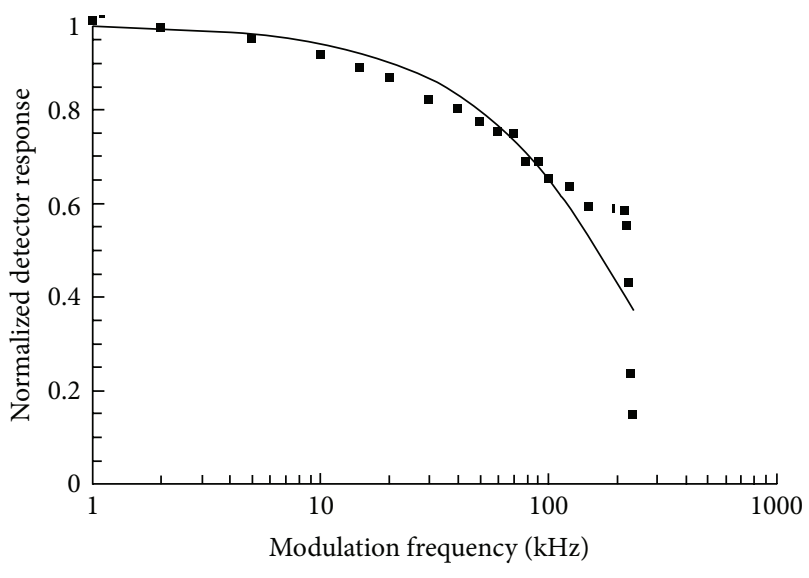

FIGURE 8: Normalized detector response (fitted) versus modulation frequency for CDRA-coupled $\mathrm{Nb}$ microbolometer on quartz substrate.

A photograph of the test setup is shown in Figure 6. The Nb microbolometer was biased at $5.03 \mathrm{~mA}$ and it had a resistance of $76 \Omega$. Niobium $(\mathrm{Nb})$ has a temperature coefficient of resistance (TCR) of $0.26 \% / \mathrm{K}$. The modulated detector response signal was amplified and captured using a lock-in amplifier referenced at the modulation frequency of the PIN switch. The modulated detector response signal was measured to be $6.86 \mu \mathrm{V}$. By using Friis transmission equation and assuming a receiving antenna gain of $7.8 \mathrm{~dB}$ (from simulations [12]), the received power by the detector is estimated to be $37.9 \mu \mathrm{W}$ and so the detector voltage responsivity is $0.181 \mathrm{~V} / \mathrm{W}$.

The normalized detected signal in both $E$ - and $H$-planes is plotted in comparison with the normalized simulated gain [12] in Figure 7. Overall, the measured radiation patterns show a good match with the simulated patterns. Discrepancies may be due to inaccuracies in the antenna simulator and also due to fabrication inaccuracies.

For time constant measurements, the modulation frequency of the PIN switch was varied and the captured detector signal was recorded. The normalized detector response as a function of the modulation frequency is plotted in Figure 8. The time constant of the detector was found to be $1.94 \mu \mathrm{s}$ which supports utilizing the detector in video frame rate imaging applications.

\section{Summary}

In this paper, we reported on the fabrication and characterization of a novel antenna-coupled microbolometer configuration for millimeter wave detection. The antenna is based on two CDRs excited by means of rectangular slots placed below the CDRs. Coplanar waveguides (CPWs) were used to feed the antenna resonant currents to an $\mathrm{Nb}$ microbolometer which was placed at the center of the CPW. The CDRAs were manufactured using a novel process which enables photolithographically patterning $\mathrm{SU}-8-\mathrm{Al}_{2} \mathrm{O}_{3}$ ceramic composites. Radiation pattern measurements for the developed detector were performed and showed a good agreement with simulated results. The detector voltage responsivity was found to be $0.181 \mathrm{~V} / \mathrm{W}$ at a modulation frequency of $150 \mathrm{~Hz}$. The detector measured a time constant of $1.94 \mu \mathrm{s}$. The value of the voltage responsivity can be improved by providing better thermal insulation for the microbolometer through suspension on a silicon nitride air bridge; nevertheless, this approach entails a complicated fabrication process. Our future work will target using high sensitivity metal-insulatormetal (MIM) diode junctions, recently developed by our research group [14] instead of microbolometers aiming for higher voltage responsivity.

\section{Conflict of Interests}

The authors declare that there is no conflict of interests regarding the publication of this paper.

\section{Acknowledgment}

This work was supported by the Annual Grants Program at King Abdulaziz City for Science and Technology (KACST) under Grant AT-4-13.

\section{References}

[1] M. Abdel-Rahman, N. Al-Khalli, A. Kusuma, and N. Debbar, "A slot antenna-coupled microbolometer for detection at $94 \mathrm{GHz}$," Progress in Electromagnetics Research Letters, vol. 32, pp. 137143, 2012.

[2] S. Nolen, J. Koch, N. Paulter, C. D. Reintsema, and E. N. Grossman, "Antenna-coupled niobium bolometers for mmwave imaging arrays," in Terahertz and Gigahertz Photonics, Proceedings of SPIE, pp. 279-286, July 1999.

[3] A. Rahman, E. Duerr, G. De Lange, and Q. Hu, "Micromachined room-temperature microbolometer for $\mathrm{mm}$-wave detection and focal-plane imaging arrays," in PassiveMillimeter-Wave Imaging Technology, Proceedings of SPIE, pp. 122-133, April 1997.

[4] A. J. Miller, A. A. Luukanen, and E. N. Grossman, "Micromachined antenna-coupled uncooled bolometers for terahertz imaging," in Terahertz for Military and Security Applications II, Proceedings of SPIE, pp. 18-24, April 2004.

[5] A. Rashidian, D. M. Klymyshyn, M. Tayfeh Aligodarz, M. Boerner, and J. Mohr, "Photoresist-based polymer resonator antennas: lithography fabrication, strip-fed excitation, and multimode operation," IEEE Antennas and Propagation Magazine, vol. 53, no. 4, pp. 16-27, 2011.

[6] A. Petosa, Dielectric Resonator Antenna Handbook, Artech House, Norwood, Mass, USA, 2007.

[7] K. M. Luk and K. W. Leung, Dielectric Resonator Antennas, Research Studies Press, 2003.

[8] A. Rashidian, D. M. Klymyshyn, M. T. Aligodarz, M. Boerner, and J. Mohr, "Photoresist-based polymer resonator antennas with permanent frame," Electronics Letters, vol. 48, no. 9, pp. 475-477, 2012.

[9] A. Rashidian, D. M. Klymyshyn, M. Tayfeh Aligodarz, M. Boerner, and J. Mohr, "Development of polymer-based dielectric resonator antennas for millimeter-wave applications," Progress In Electromagnetics Research C, vol. 13, pp. 203-216, 2010. 
[10] A. Rashidian, M. T. Aligodarz, D. Klymyshyn, M. Boerner, L. Shafai, and J. Mohr, "Photoresist-based dielectric resonator antenna fabrication and performance: a review," in Proceedings of the 16th International Symposium on Antenna Technology and Applied Electromagnetics (ANTEM '14), pp. 1-2, July 2014.

[11] S. George, S. Raman, P. Mohanan, and M. T. Sebastian, "Polymer ceramic composites for microwave substrate and antenna applications," in Proceedings of the Indian Antenna Week A Workshop on Advanced Antenna Technology, pp. 1-4, IEEE, Puri, India, June 2010.

[12] M. K. Saleem, M. Abdel-Rahman, M. Alkanhal, and A. Sebak, "A cylindrical dielectric resonator antenna-coupled sensor configuration for $94 \mathrm{GHz}$ detection," International Journal of Antennas and Propagation, vol. 2014, Article ID 850736, 5 pages, 2014.

[13] S. Singha and M. J. Thomas, "Dielectric properties of epoxy nanocomposites," IEEE Transactions on Dielectrics and Electrical Insulation, vol. 15, no. 1, pp. 12-23, 2008.

[14] M. Abdel-Rahman, M. Syaryadhi, and N. Debbar, "Fabrication and characterisation of high sensitivity copper-copper oxidecopper (Cu-CuO-Cu) metal-insulator-metal tunnel junctions," Electronics Letters, vol. 49, no. 5, pp. 363-364, 2013. 

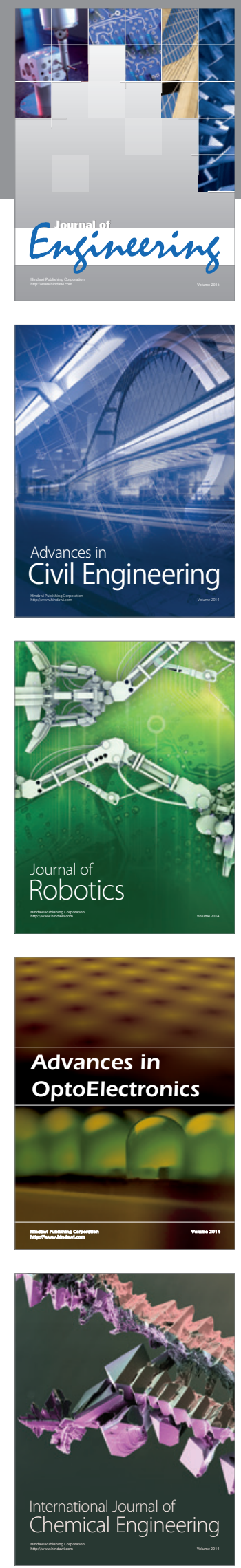

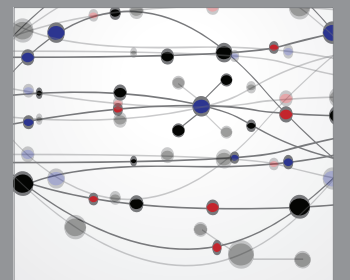

The Scientific World Journal
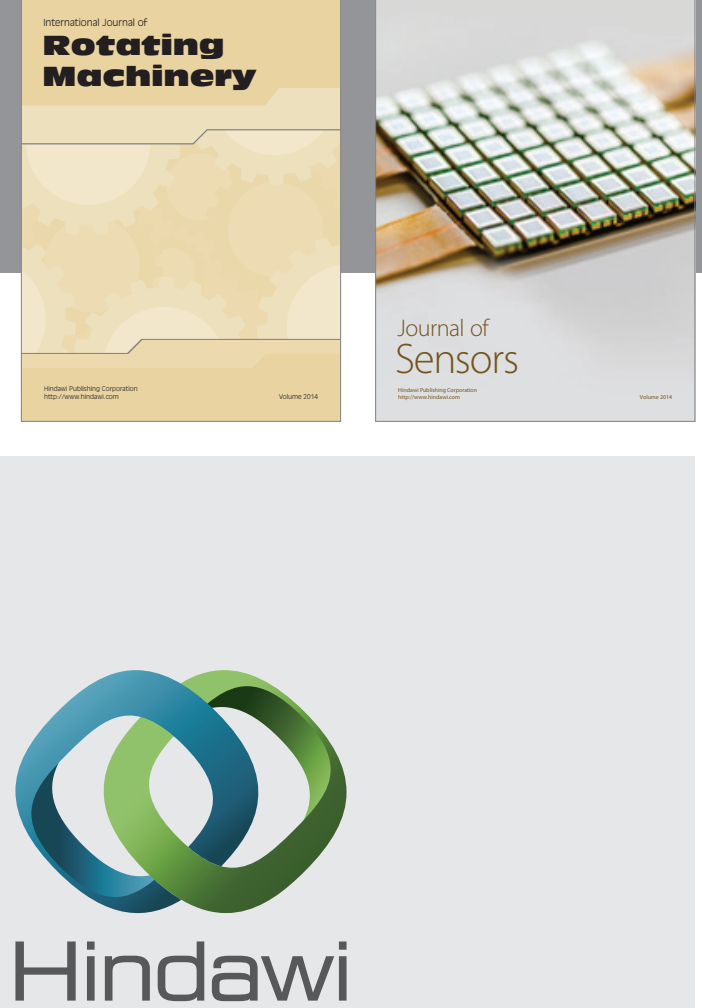

Submit your manuscripts at http://www.hindawi.com
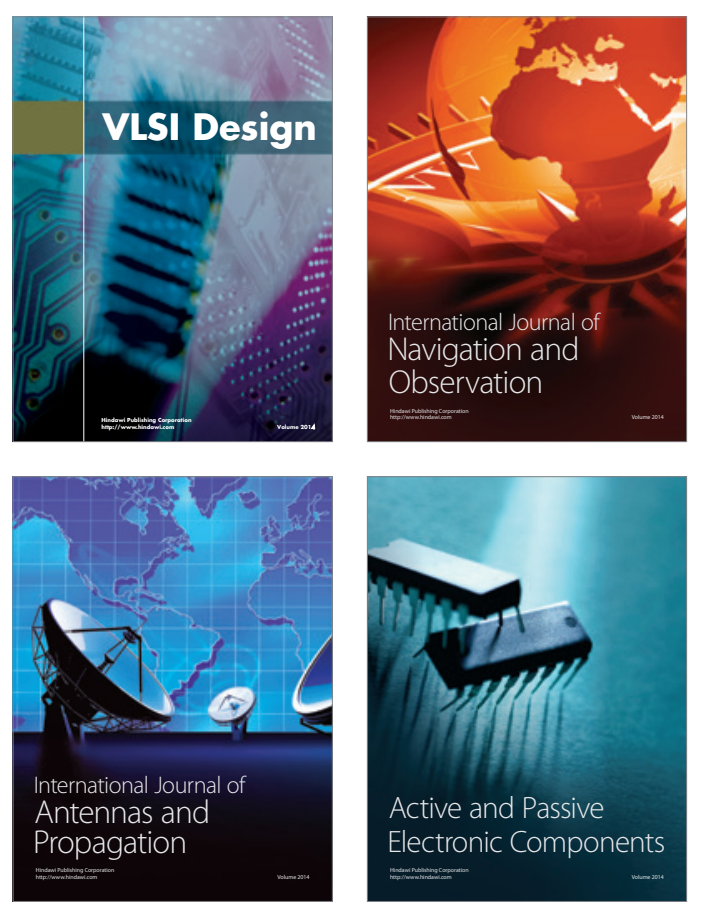
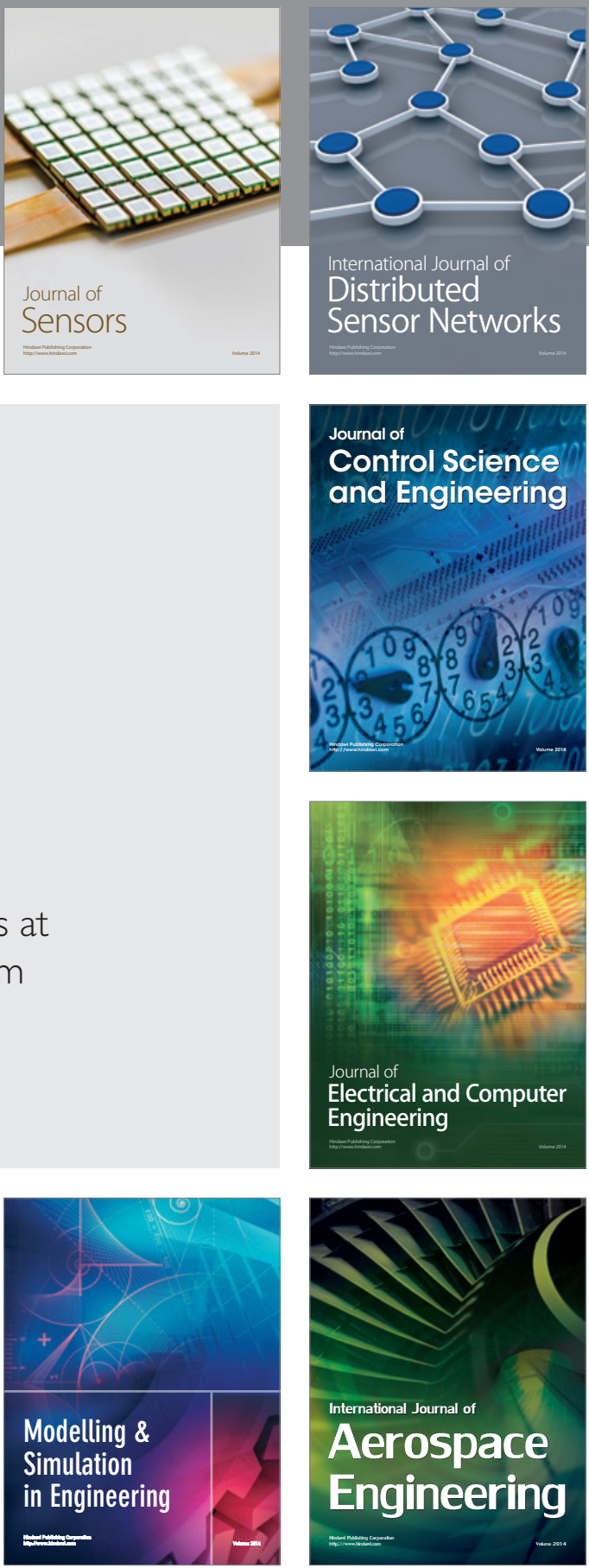

Journal of

Control Science

and Engineering
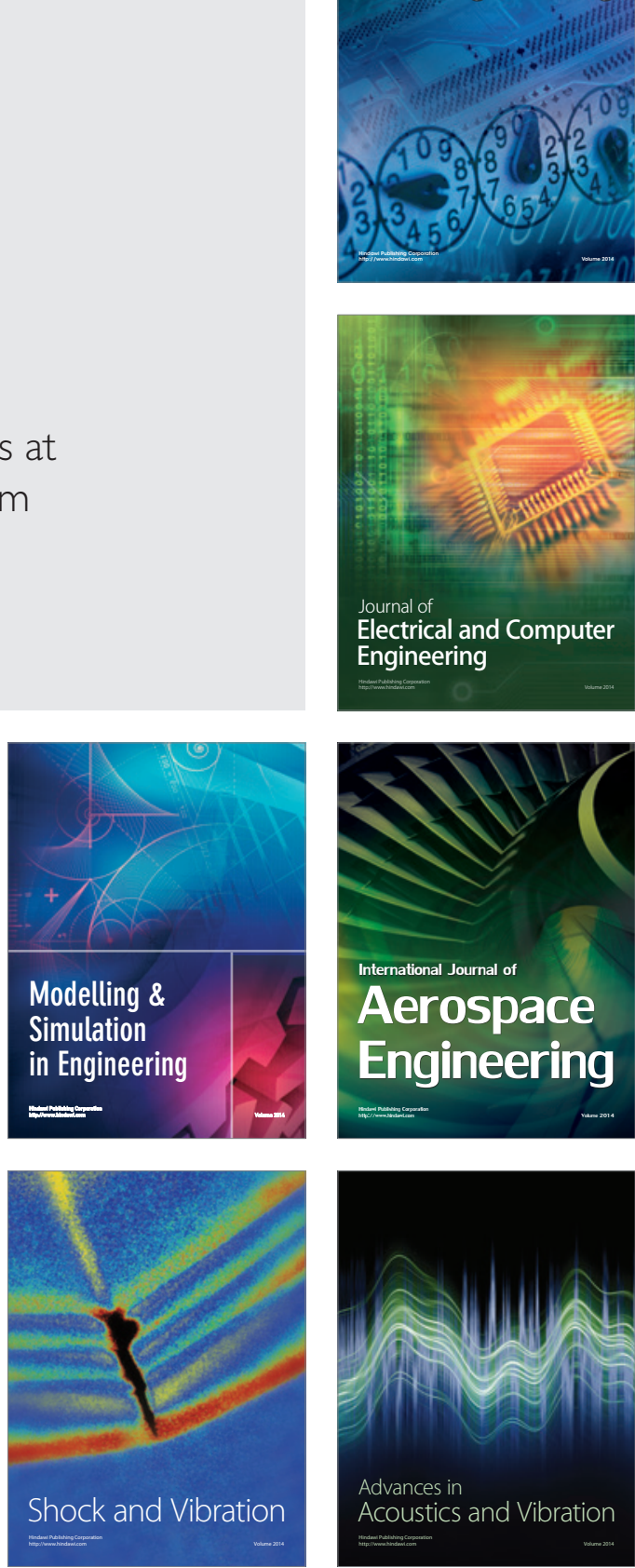